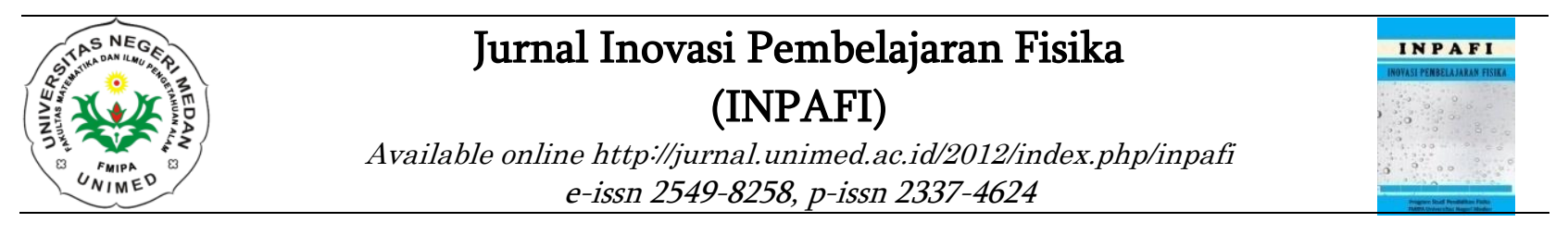

\title{
PENGARUH MODEL PEMBELAJARAN KOOPERATIF TIPE GROUP INVESTIGATION DIPADU MIND MAPPING TERHADAP HASIL BELAJAR SISWA PADA MATERI MOMENTUM DAN IMPULS DI SMA N 14 MEDAN
}

\author{
Sri Rahayu Harahap dan Mukti Hamjah Harahap \\ Jurusan Fisika FMIPA Universitas Negeri Medan \\ srirahayuharahap05@gmail.com,hmuktihamjah@yahoo.co.id \\ Diterima: Desember 2018. Disetujui: Januari 2019. Dipublikasikan: Februari 2019
}

\begin{abstract}
ABSTRAK
Penelitian ini bertujuan untuk mengetahui pengaruh model pembelajaran kooperatif tipe GI dipadu mind mapping terhadap hasil belajar siswa pada materi momentum dan impuls di kelas X MIPA SMA N 14 Medan tahun ajaran 2017/2018. Jenis penelitian ini adalah quasi exsperiment dengan two group pretest-postest design. Populasi dalam penelitian ini adalah seluruh siswa kelas X MIPA SMA N 14 Medan Tahun Ajaran 2017/2018 yang terdiri dari 7 kelas. Pengambilan sampel dilakukan dengan random sampling terdiri dari dua kelas yaitu kelas X MIPA 4 sebagai kelas eksperimen yang diberi perlakuan model pembelajaran kooperatif tipe GI dipadu mind mapping dan kelas X MIPA 5 sebagai kelas kontrol yang diberi perlakuan dengan pembelajaran konvensional. Masing-masing kelas terdiri dari 25 siswa. Instrumen yang digunakan untuk mengetahui hasil belajar siswa adalah tes hasil belajar berbetuk pilihan berganda dengan jumlah 15 soal yang sudah divalidasi, lembar penilaian aktivitas belajar siswa, dan penilaian mind mapping. Hasil pengujian hipotesis dengan menggunakan uji t dengan $\alpha=0,01$ diperoleh ada perbedaan yang signifikan dari model pembelajaran kooperatif tipe GI dipadu mind mapping terhadap hasil belajar siswa pada materi momentum dan impuls di SMA N 14 Medan.
\end{abstract}

Kata Kunci: model pembelajaran kooperatif tipe group investigation, mind mapping, hasil belajar.

\begin{abstract}
This study aims to determine the effect of GI-type cooperative learning models combined with mind mapping on student learning outcomes in the material of momentum and impulse in class X MIPA SMA N 14 Medan academic year 2017/2018. This type of research is quasiexperimental with two groups pretest-posttest design. The population in this study were all students of class X MIPA SMA N 14 Medan 2017/2018 school year consisting of 7 classes. Sampling was done by random sampling consisting of two classes, namely class X MIPA 4 as an experimental class which was treated with GI type learning model combined with mind mapping and class X MIPA 5 as a control class treated with conventional learning. Each class consists of 25 students. The instrument used to determine student learning outcomes is a multiple-choice learning outcomes test with a total of 15 validated questions, an assessment sheet of student learning activities, and mind mapping assessment. The results of testing hypotheses using $t$ test with $\alpha=0.01$ obtained that there is a significant difference from the
\end{abstract}


Sri Rahayu Harahap dan Mukti Hamjah Harahap; Pengaruh Model Pembelajaran Kooperatif Tipe Group Investigation dipadu Mind Mapping terhadap Hasil Belajar Siswa pada Materi Momentum dan Impuls di SMA N 14 Medan

GI type cooperative learning model combined with mind mapping on student learning outcomes in the material of momentum and impulse in SMA N 14 Medan.

Keywords: GI-type cooperative learning, mind mapping, learning outcomes

\section{PENDAHULUAN}

Pengembangan ilmu pengetahuan dan teknologi pada era globalisasi menuntut terbentuknya sumber daya manusia yang berkualitas. Mendapatkan kualitas sumber daya manusia yang unggul tentu diperlukan usaha dan kerja keras dari berbagai pihak terutama dalam bidang pendidikan. Pendidikan yang baik adalah pendidikan yang mampu mengembangkan potensi peserta didik, sehingga yang bersangkutan mampu menghadapi dan memecahkan problema kehidupan yang dihadapinya.

Kualitas pendidikan di Indonesia masih jauh dari yang diharapkan. Beberapa permasalahan terkait dengan kualitas pendidikan adalah rendahnya mutu pendidikan khususnya pada pelaksanaan proses pembelajaran.

Berdasarkan hasil studi pendahuluan di SMA N 14 Medan sebanyak $69 \%$ siswa menyatakan bahwa fisika sulit dipahami, dan sebanyak 57 \% siswa menyatakan bahwa mereka merasa bosan saat belajar fisika. Pelaksanaan pembelajaran memicu rendahnya hasil belajar yang di peroleh oleh siswa. Pelaksanaan pembelajaran yang cenderung berpusat pada guru membuat siswa tidak melakukan partisipasi dalam pembelajaran, karena siswa hanya mendengar informasi yang disampaikan oleh guru sehingga siswa menjadi bosan saat belajar fisika. Sinulingga dan Munte (2012) menyatakan bahwa pembelajaran konvensional menyebabkan partisipasi siswa di dalam belajar Fisika rendah yang berdampak pada hasil belajar siswa yang rendah pula. Berdasarkan hasil studi pendahuluan bahwa sebanyak $72 \%$ siswa menyatakan lebih mudah memahami pelajaran fisika dengan diskusi kelompok. Berdasarkan pemaparan tersebut perlu dilakukannya pembelajaran dengan diskusi kelompok agar siswa lebih mudah memahami materi dan siswa tidak merasa bosan saat pembelajaran.
Salah satu model pembelajaran dengan diskusi kelompok adalah pembelajaran kooperatif. Pembelajaran kooperatif muncul dari konsep bahwa siswa akan lebih mudah menemukan dan memahami konsep yang sulit jika mereka saling berdiskusi dengan temannya (Trianto, 2016). Pembelajaran dengan mengandalkan interaksi sosial dapat disiasati untuk meningkatkan hasil pembelajaran (Joyce, dkk, 2009).

Fisika adalah cabang ilmu pengetahuan yang membahas mengenai gejala-gejala alam, seharusnya fisika dapat menarik minat siswa untuk mempelajarinya. Kenyataannya, fisika merupakan salah satu mata pelajaran yang dianggap sulit oleh siswa. Fisika merupakan salah satu mata pelajaran IPA. Mata pelajaran IPA bukanlah berisi kumpulan pengetahuan yang dapat dihafal tetapi merupakan pelajaran yang berisikan cara mencari tahu tentang alam semesta. Berdasarkan studi pendahuluan bahwa sebanyak $68 \%$ siswa melakukan penyelidikan terhadap sesuatu hal yang tidak mereka ketahui. GI adalah salah satu tipe pembelajaran kooperatif yang dapat membuat siswa mencari tahu dan membangun pengetahuannya sendiri yang dilakukan pada tahap investigasi. GI merupakan salah satu pembelajaran yang inovatif sehingga siswa dapat membangun pengetahuannya sendiri (Solichah, dkk, 2015).

Setelah siswa mendapatkan informasi dari kegiatan investigasi, ada baiknya siswa diarahkan untuk memetakan informasi yang didapat agar pengetahuan yang didapat menjadi lebih terarah. Biasanya kebanyakan siswa setelah mendapatkan informasi, jika sudah keluar dari kelas siswa lupa dengan apa yang sudah dipelajari, apalagi siswa tidak mencatat informasi yang sudah didapatnya. Berdasarkan hasil angket yang disebarkan pada 33 orang siswa kelas $\mathrm{X}$ hanya $3 \%$ siswa selalu ingat dengan materi yang sebelumnya telah dipelajari, sehingga agar membantu siswa mudah mengingat meteri yang 
dipelajari dibutuhkan teknik mencatat yang baik. Salah satu teknik mencatat yang dapat menyimpan informasi dan lebih mudah diingat adalah mind mapping dibandingkan dengan menggunakan teknik mencatat tradisional (Wati dan Siswanti, 2015). Berdasarkan studi pendahuluan bahwa $73 \%$ siswa suka mencatat dengan simbol-simbol dibandingkan mencatat dengan mengarang panjang. Mind mapping melibatkan kombinasi unik dari citra, warna dan pengaturan visual-spasial yang terbukti secara signifikan meningkatkan daya ingat bila dibandingkan dengan metode konvensional mencatat dan belajar dengan hafalan. Seperti penelitian yang dilakukan oleh Risnawati, dkk (2015) bahwa penerapan pembelajaran aktif berbasis mind mapping dapat meningkatkan daya ingat peserta didik.

Berdasarkan uraian di atas, maka peneliti melakukan penelitian untuk mengetahui pengaruh model pembelajaran kooperatif tipe GI dipadu mind mapping terhadap hasil belajar siswa pada materi momentum dan impuls di SMA N 14 medan.

\section{METODE PENELITIAN}

Penelitian ini dilaksanakan di SMA N 14 Medan dengan populasi seluruh siswa kelas X MIPA semester II tahun ajaran 2017/2018 yang berjumlah 7 kelas. Sampel penelitian yaitu kelas X MIPA 4 sebagai kelas eksperimen yang diberi perlakuan model pembelajaran kooperatif tipe GI dipadu mind mapping dan kelas $\mathrm{X}$ MIPA 5 sebagai kelas kontrol yang diberi perlakuan pembelajaran konvensional. Siswa pada kedua kelas berjumlah 25 siswa. Teknik pengambilan sampel dilakukan dengan random sampling.

Jenis penelitian ini ialah quasi exsperiment dengan two group pretest-postest design. Instrumen yang digunakan dalam penelitian adalah tes pilihan berganda yang berjumlah 15 butir, lembar aktivitas, dan lembar penilaian mind mapping. Pengaruh adanya model pembelajaran kooperatif tipe GI dipadu mind mapping dianalisis dengan uji satu pihak.

\section{HASIL DAN PEMBAHASAN}

\section{a. Hasil Penelitian}

Hasil data pretes pada kelas eksperimen diperoleh nilai rata-rata 25,35 dan dan pada kelas kontrol diperoleh nilai rata-rata 24,28 . Setelah itu kedua kelas diberi perlakuan. Kelas eksperimen diberi perlakuan dengan model kooperatif tipe GI dipadu mind mapping dan kelas kontrol diberi perlakuan dengan pembelajaran konvensional. Setelah diberi perlakuan kedua kelas diberikan postes. Hasil data postes pada kelas eksperimen diperoleh nilai rata-rata 57,63 dan pada kelas kontrol diperoleh nilai rata-rata 44,29. Data pretes dan postes kelas eksperimen dan kelas kontrol ditunjukkan pada Gambar 1.

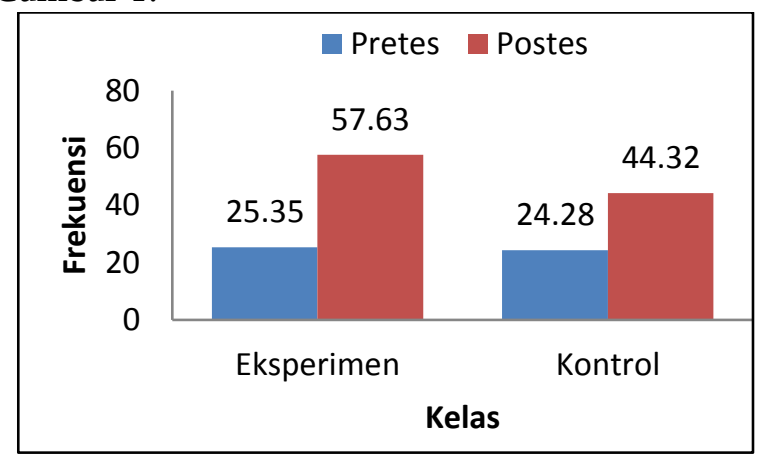

Gambar 1. Data pretes dan postes kelas eksperimen dan kelas kontrol

Sebelum menganalisis uji hipotesis dilakukan uji prasyarat yaitu uji normalitas dan uji homogenitas. Uji normalitas dengan menggunakan uji Lilliefors, data pretes dan data postes diperoleh bahwa kedua sampel berdistribusi normal. Uji normalitas data pretes dan data postes kedua sampel ditunjukkan pada Tabel 1.

Tabel 1. Uji normalitas data pretes dan data postes kelas eksperimen

\begin{tabular}{|c|c|c|c|c|c|c|}
\hline \multirow{2}{*}{ Kelas } & \multicolumn{2}{|c|}{ Pretes } & Kesimp & \multicolumn{2}{|c|}{ Postes } & \multirow{2}{*}{ Kesimp } \\
\cline { 2 - 3 } \cline { 5 - 6 } & Lhitung & Ltabel & ulan & Lhitung & Ltabel & ulan \\
\hline Eksperi & 0,131 & 0,20 & normal & 0,154 & 0,20 & normal \\
men & 4 & 0 & & 9 & 0 & \\
\hline Kontro & 0,185 & 0,20 & normal & 0,182 & 0,20 & normal \\
1 & 4 & 0 & & 1 & 0 & \\
\hline
\end{tabular}

Setelah kedua sampel berdistribusi normal, dilakukan uji homogenitas untuk mengetahui apakah kedua sampel berasal dari populasi yang 
Sri Rahayu Harahap dan Mukti Hamjah Harahap; Pengaruh Model Pembelajaran Kooperatif Tipe Group Investigation dipadu Mind Mapping terhadap Hasil Belajar Siswa pada Materi Momentum dan Impuls di SMA N 14 Medan

homogen atau tidak. Hasil uji homogen data pretes dan data postes kedua sampel ditunjukkan pada Tabel 2.

Tabel 2. Uji homogenitas data pretes dan data postes kedua sampel

\begin{tabular}{|c|c|c|c|c|c|}
\hline \multicolumn{2}{|c|}{ Pretes } & \multirow{2}{*}{$\begin{array}{c}\text { Kesimpula } \\
\mathrm{n}\end{array}$} & \multicolumn{2}{|c|}{ Postes } & \multirow{2}{*}{$\begin{array}{c}\text { Kesimpula } \\
\mathrm{n}\end{array}$} \\
\hline F hitung & $F_{\text {tabel }}$ & & Fhitung & $F_{\text {tabel }}$ & \\
\hline 2,31 & 2,66 & homogen & 2,58 & 2,66 & homogen \\
\hline
\end{tabular}

Pengujian hipotesis, data pretes dilakukan uji dua pihak untuk mengetahui kesamaan kemampuan awal siswa. Hasil uji dua pihak ditunjukkan pada Tabel 3.

Tabel 3. Uji dua pihak data pretes

\begin{tabular}{|c|c|c|}
\hline \multicolumn{2}{|c|}{ Uji Dua Pihak } & Kesimpulan \\
\hline thitung & ttabel & \\
\hline 0,37 & 2,68 & $\begin{array}{c}\text { kemampuan awal } \\
\text { siswa kedua sampel } \\
\text { sama }\end{array}$ \\
\hline
\end{tabular}

Data postes dilakukan uji satu pihak. Hasil uji satu pihak ditunjukkan pada Tabel 4 .

Tabel 4. Uji satu pihak data postes

\begin{tabular}{|c|c|c|}
\hline \multicolumn{2}{|c|}{ Uji Satu Pihak } & \multirow{2}{*}{ Kesimpulan } \\
\hline thitung & ttabel & \\
\hline 3,63 & 2,4 & $\begin{array}{c}\text { adanya perbedaan } \\
\text { yang signifikan }\end{array}$ \\
\hline
\end{tabular}

Hasil uji hipotesis dengan menggunakan uji satu pihak dengan $\alpha=0,01$ diperoleh bahwa $t_{\text {hitung }}>t_{\text {tabel }}$, dengan demikian ada perbedaan yang signifikan dari model pembelajaran kooperatif tipe GI dipadu mind mapping terhadap hasil belajar siswa pada materi momentum dan impuls di SMA N 14 Medan.

Hasil observasi aktivitas belajar siswa di kelas eksperimen mengalami peningkatan tiap pertemuan dengan model pembelajaran kooperatif tipe GI dipadu mind mapping. Observasi aktivitas belajar siswa ditunjukkan pada Gambar 2.

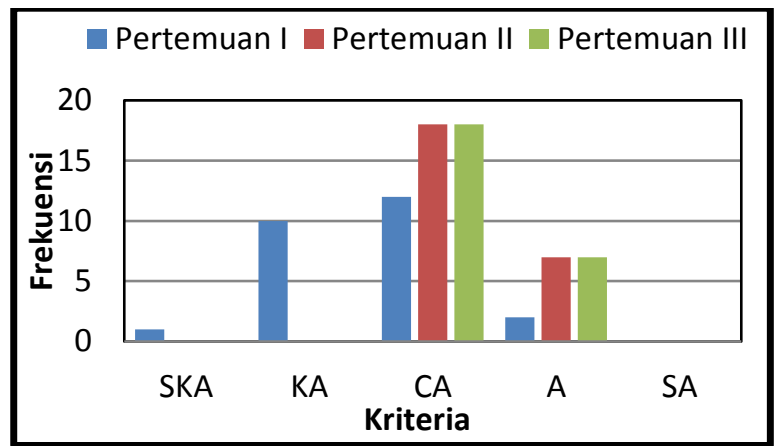

Gambar 2. Aktivitas belajar siswa pada kelas eksperimen tiap pertemuan

Uji korelasi aktivitas belajar siswa dengan hasil belajar ditunjukkan pada Tabel 5 .

Tabel 5. Uji korelasi aktivitas belajar siswa dengan hasil belajar

\begin{tabular}{|c|c|c|}
\hline $\begin{array}{c}\text { Koefisien } \\
\text { Korelasi }\end{array}$ & Keterangan & $\begin{array}{c}\text { Koefisien } \\
\text { Determinasi (\%) }\end{array}$ \\
\hline 0,68 & $\begin{array}{c}\text { korelasi } \\
\text { tinggi }\end{array}$ & 46,24 \\
\hline
\end{tabular}

Setelah melakukan investigasi, siswa membuat mind mapping dari informasi yang didapat dari kegiatan investigasi. Adapun nilai mind mapping yang dibuat oleh siswa ditunjukkan pada Gambar 3.

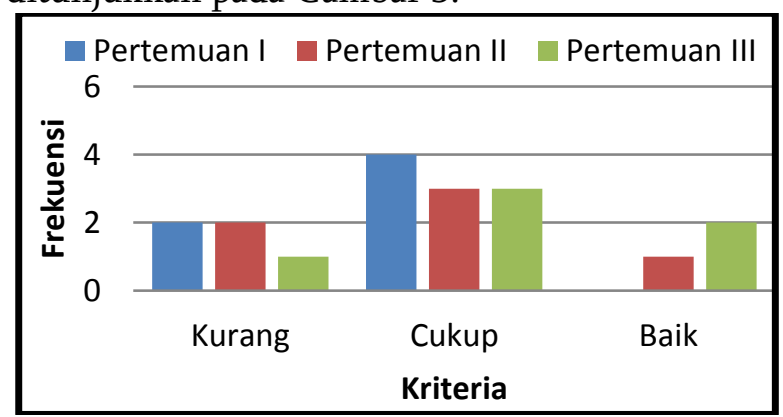

Gambar 3. Nilai mind mapping pada kelas eksperimen

Uji korelasi antara nilai mind mapping dengan hasil belajar ditunjukkan pada Tabel 6 .

Tabel 6. Uji korelasi nilai mind mapping dengan hasil belajar

\begin{tabular}{|c|c|c|}
\hline $\begin{array}{c}\text { Koefisien } \\
\text { Korelasi }\end{array}$ & Keterangan & $\begin{array}{c}\text { Koefisien } \\
\text { Determinasi (\%) }\end{array}$ \\
\hline 0,6 & $\begin{array}{c}\text { korelasi } \\
\text { cukup }\end{array}$ & 36 \\
\hline
\end{tabular}




\section{b. Pembahasan}

Hasil penelitian menunjukkan bahwa hasil belajar siswa kelas eksperimen lebih baik dibandingkan hasil belajar siswa pada kelas kontrol. Hasil penelitian ini sejalan dengan penelitian yang dilakukan oleh Lubis,dkk (2017), Derlina dan Hasanah (2017), Mulia (2017) yang menyatakan bahwa hasil belajar siswa dengan menggunakan model kooperatif tipe GI lebih baik dibandingkan dengan hasil belajar siswa dengan pembelajaran konvensional.

Hasil belajar menggunakan model kooperatif tipe GI dipadu mind mapping lebih baik karena model kooperatif tipe GI lebih banyak mengaktifkan kegiatan belajar siswa dibandingkan dengan kegiatan guru. Siswa saling membantu dalam menyelesaikan tugas yang diberikan, siswa juga lebih leluasa untuk saling bertanya dan mengemukakan pendapat bersama teman dalam kegiatan diskusi kelompok. Sejalan dengan penelitian yang dilakukan oleh Derlina dan Hasanah (2017) yang menyatakan bahwa hubungan kooperatif dalam kelompok belajar menginspirasi siswa untuk memiliki keberanian untuk mengekspresikan pendapat, berkomunikasi dan berbagi informasi dengan teman dalam memecahkan masalah belajar. Amelda dan Sahyar (2017) juga menyatakan bahwa pembelajaran kooperatif tipe GI dapat meningkatkan tingkat partisipasi dalam diskusi kelompok untuk memecahkan masalah yang dihadapi saat melakukan investigasi.

Siswa secara langsung melakukan kegiatan eksperimen dan dibantu dengan pertanyaan-pertanyaan yang ada di LKS sehingga siswa berusaha mencari jawaban dari pertanyaan-pertanyaan yang ada di LKS, terlebih lagi bahwa ada beberapa soal dalam tes hasil belajar yang diambil dari kegiatan eksperimen yang dilakukan.

Aktivitas belajar siswa yang dilihat dari tahap-tahap model kooperatif tipe GI menunjukkan bahwa aktivitas belajar siswa mengalami peningkatan tiap pertemuan. Peningkatan terjadi pada tahap mengidentifikasi topik yaitu siswa sudah mulai memperhatikan permasalahan atau isu yang disajikan. Tahap investigasi, siswa sudah lebih mandiri dalam melakukan investigasi dan tiap anggota kelompok mulai berdistribusi dengan baik untuk kelompoknya dan sumber belajar yang mereka gunakan lebih dari satu, yaitu mereka menggunakan bahan bacaan dan berdiskusi. Selanjutnya peningkatan terjadi pada tahap mempresentasikan laporan, yaitu siswa mempresentasikan dengan bahasa yang baik dan membuat keterlibatan teman sekelasnya dengan membuat pertanyaan. Sejalan dengan penelitian yang dilakukan oleh Simanjuntak dan Siregar (2014) yang menyatakan bahwa aktivitas belajar siswa dengan menggunakan model kooperatif tipe GI mengalami peningkatan tiap pertemuan. Berdasarkan uji korelasi antara aktivitas belajar siswa dengan hasil belajar siswa diperoleh makna bahwa aktivitas belajar siswa berkorelasi tinggi terhadap hasil belajar siswa. Setelah itu diperoleh juga koefisien determinasi sebesar $46,24 \%$, yang artinya aktivitas belajar siswa berkontribusi sebesar 46,24\% terhadap hasil belajar siswa. Sejalan dengan penelitian yang dilakukan oleh Wianti (2010) bahwa ada pengaruh dari aktivitas belajar siswa terhadap hasil belajar.

Setelah mendapatkan informasi siswa diarahkan untuk memetakan informasi tersebut dengan teknik mencatat mind mapping. Mind mapping yang dibuat oleh siswa kemudian dinilai oleh peneliti. Kelompok siswa yang mind mappingnya tergolong dalam kategori baik ternyata hasil postesnya juga mencapai ketuntasan. Berdasarkan uji korelasi diperoleh bahwa korelasi nilai mind mapping dengan hasil belajar tergolong kategori cukup dan diperoleh koefisien determinasi sebesar $36 \%$, yang artinya mind mapping berkontribusi sebesar 36\% terhadap hasil belajar siswa. Sejalan dengan penelitian yang dilakukan oleh Simanjuntak dan Batubara (2013) yang menyatakan bahwa penggunaan peta pikiran juga mempengaruhi hasil belajar siswa.

Selama penerapan model kooperatif tipe GI dipadu mind mapping peneliti mengalami beberapa kendala, diantaranya 1) Siswa belum 
Sri Rahayu Harahap dan Mukti Hamjah Harahap; Pengaruh Model Pembelajaran Kooperatif Tipe Group Investigation dipadu Mind Mapping terhadap Hasil Belajar Siswa pada Materi Momentum dan Impuls di SMA N 14 Medan

terbiasa belajar dengan menggunakan model kooperatif tipe GI dipadu mind mapping; 2) Waktu yang digunakan tidak sesuai dengan rancangan RPP, hal ini disebabkan peraturan dari pihak sekolah yang berdampak pada penggunaan waktu yang kurang dalam proses penelitian; 3) Masih ada siswa yang acuh dan tidak perduli dengan apa yang disampaikan dan diselidiki.

Kelemahan dalam penelitian ini ialah 1) Pembagian kelompok yang tidak heterogen, padahal seharusnya kelompok yang heterogen menguntungkan bagi semua anak. Menurut Arends (2008) diasumsikan bahwa siswa-siswa dengan kemampuan kurang, belajar lebih banyak dengan bekerja berdampingan dengan mereka yang memiliki kemampuan lebih dan bahwa kelompok yang berkemampuan lebih ini mendapatkan manfaat dari proses berperan sebagai tutor bagi teman-temannya yang kurang mampu; 2) Peneliti tidak memberikan motivasi pada awal pembelajaran, sejalan dengan penelitian yang dilakukan oleh Vellayati (2017) yang menyatakan bahwa salah satu faktor yang mempengaruhi aktivitas belajar siswa ialah motivasi; 3) Pembuatan mind mapping yang dilakukan oleh siswa tergolong dalam kategori kurang, cukup dan baik. Kelompok siswa yang tergolong kategori cukup dan kurang dalam membuat mind mapping disebabkan oleh siswa belum terbiasa mencatat dengan tehnik mind mapping. Sejalan dengan penelitian yang dilakukan oleh Suratmi dan Noviyanti (2013) yang menyatakan bahwa kebiasaan lama dalam tehnik mencatat berpengaruh terhadap teknik mencatat mind mapping. Siswa belum mengerti cara pembuatan mind mapping namun tidak ingin bertanya, sehingga hasil pembuatan mind mapping tidak seperti yang diharapkan. Sejalan dengan penelitian Simanjuntak dan Batubara (2013) bahwa hasil pembuatan peta pikiran tidak seperti yang diharapkan karena siswa belum memahami cara pembuatan peta pikiran. Selain itu pembuatan mind mapping dilakukan perkelompok sehingga penilaian yang dilakukan juga perkelompok. Hal ini menyebabkan tidak diketahuinya siswa yang mengerti membuat mind mapping dan siswa yang tidak mengerti membuat mind mapping.

\section{KESIMPULAN DAN SARAN}

\section{Kesimpulan}

Berdasarkan data hasil penelitian yang telah dianalisis dengan statistik diperoleh bahwa nilai postes kelas eksperimen lebih tinggi dibandingkan nilai postes kelas kontrol, sehingga dapat dikatakan bahwa ada perbedaan yang signifikan dari model kooperatif tipe GI dipadu mind mapping terhadap hasil belajar siswa pada materi momentum dan impuls di SMA N 14 Medan.

\section{Saran}

Sebagai tindak lanjut dari penelitian ini dalam proses pembelajaran sebaiknya memberikan motivasi terlebih dahulu sebelum memulai pembelajaran, pembagian kelompok secara heterogen yang dapat dilakukan dengan mengaitkan hasil pretes, pengelolaan waktu yang sesuai dengan RPP agar penelitian selanjutnya lebih baik lagi, dan pembuatan mind mapping dilakukan perindividu sehingga pengaruh mind mapping terhadap hasil belajar lebih jelas lagi.

\section{DAFTAR PUSTAKA}

Amelda, R., dan Sahyar, (2017), Effect of Cooperative Learning Model Type Group Investigation Assisted PhET to Student's Conceptual Knowledge, IOSR Journal of Research \& Method in Education (IOSRJRME), 7(4) : 75-80.

Arends, R. I., (2008), Learning to Teach, Pustaka Pelajar, Yogyakarta.

Derlina dan Hasanah, N., (2017), Influence of Cooperative Type Model of Group Investigation on Student's Cognitive Learning Outcomes, Proceedings of ICSoTL 2017, 174-178. 
Joyce, B., Weil, M., dan Calhoun, E., (2009), Models Of Teaching, Pustaka Pelajar, Yogyakarta.

Lubis, R. H., Sani, R. A., dan Juliani, R., (2017) Pengaruh Model Pembelajaran kooperatif Tipe Group Investigation terhadap Hasil Belajar Fisika ditinjau dari Adversity Quetient Siswa, Jurnal Pendidikan Fisika, 6(1) : 44-49.

Mulia, N., (2017), Pengaruh Model Pembelajaran Kooperatif Tipe Group Investigation terhadap Hasil Belajar Siswa pada Materi Elastisitas dan Hukum Hooke di Kelas XI Semester I SMA Muhammadiyah 02 Medan Tahun Pelajaran 2017/2018, Skripsi, FMIPA, UNIMED, Medan.

Risnawati, Rachmatiah, dan Wardani, N., K., Subaer, (2015), Penerapan Pembelajaran Aktif Berbasis Mind Mapping untuk Meningkatkan Daya Ingat dan Hasil Belajar Fisika Unit Suhu dan Pemuaian pada Siswa Kelas VII SMP Negeri 24 Makassar, Prosiding Pertemaun Ilmiah XXIX HFI Jateng \& DIY, 293-296.

Simanjuntak, M. P., dan Batubara, S. N., (2013), Pengaruh Model Pembelajaran Advance Organizer Berbasis Peta Pikiran Terhadap Hasil Belajar Fisika Siswa SMA Negeri 1 Percut Sei Tuan, Jurnal Inpafi, 1(3) : 311318.

Simanjuntak, S. L., dan Siregar, N., (2014) Pengaruh Model Pembelajaran Kooperatif Tipe Group Investigation Terhadap Hasil Belajar Siswa pada Materi Listrik Dinamis, Jurnal Inpafii, 2(2) : 171179.

Sinulingga, K., dan Munte, D., (2012), Pengaruh Model Pembelajaran Anvance Organizer Berbasis Mind Map Terhadap Hasil Belajar Fisika Siswa Pada Materi Pokok
Besaran dan Satuan di Kelas X SMA, Jurnal Pendidikan Fisika, 1(2) : 1-6.

Solichah, T. M., Prihandono, T., dan Yushardi, (2015), Implementasi Model Group Investigation (GI) Berbasis Masalah Kontekstual Dipadu penilaian Proyek Pada pembelajaran Fisika di MA, Jurnal Edukasi UNEJ, 2(1) : 20-23.

Suratmi dan Noviyanti, F., (2013), Penggunaan Mind Map sebagai Instrumen Penilaian Hasil Belajar Siswa pada Pembelajaran Konsep Reproduksi di SMPN 1 Anyar, Jurnal Semirata 2013 FMIPA Unila, 393398.

Trianto, (2016), Mendesain Model Pembelajaran Inovatif-Progresif, Kencana, Jakarta.

Vellayati, S., (2017), Analisis Aktivitas Belajar Siswa dan Aktivitas Pembelajaran Guru pada Mata pelajaran Kimia, Prosiding Seminar Nasional MIPA III, 119-126.

Wati, M. L., dan Siswati, (2015), Pengaruh Metode Mind Map Terhadap Peningkatan Hasil Belajar Mata Pelajaran Ilmu Pengetahuan Alam Terpadu Pada Siswa Kelas VII, Jurnal Empati, 4(4) : 131138.

Wianti, A., (2010), Pengaruh Aktivitas Belajar Siswa Terhadap Hasil Belajar Geografi pada sekolah Menengah Atas di Kecamatan Gombong Kabupaten Kabumen, Skripsi, UNNES, Semarang. 